\title{
الترجمة معناهاوتاريخها
}

Raswan $^{1}$

\begin{abstract}
Abstrak
Terjemahan adalah fakta kebutuhan kemanusiaan, karena manusia berbicara dalam bahasa yang berbeda antar masyarakat dan Negara yang berbeda. Tenerjemah juga dilakukan untuk memenuhi kebutuhan interaksi antara masyarakat dari berbagai negara dalam bahasa. Demikian juga bahwa manusia diberikan naluri cinta il mu pengetahun, senang mengkritik dan mencintai ilmu yang berkembang di berbagai penjuru dunia dan untuk menguasaiilmu tersebut maka manusia mau tidak mau harus menguasai bahasa yang digunakan oleh bangsa yang ilmu tersebut berkembang di bangsa tersebut. Terjemah juga merupakan factor utama penentu kemajuan sebuah bangsa dan mayoritas Negara maju di di dunia adalah Negara yang memperhatikan gerakan terjemah di negaranya. Dan terjemah menurut sejarah diawali dengan gerakan terjemah ke dalam bahasa Yunan, gerkan terjemah ke dalam bahasa Suryani, gerakan terjemah ke dalam bahasa Arab di masa khulafau ar-rasyidin (Muawiyyah dan Abbasyiyyah), gerakan terjemah ke dalam bahasa latin, gerakan terjemah ke dalam bahasa Eropa modern, gerakan terjemah modern ke dalam bahasa Arab dan bahasa-bahasa lain di dunia dari bahasa Inggris sebagai bahasa yang penuturnya sedang mengalami kemajun.
\end{abstract}

Kata Kunci: penerjamahan, bahasa, hasil terjamahan, proses penerjamahan

\begin{abstract}
Translation is the fact humanitarian needs, because people speaking in different languages between communities and different countries. Translations also done to meet the needs of interaction between people from different countries in the language. Similarly, given that the human instinct is love the knowledge, pleasure and love to criticize science developed in various parts of the world and to the human master science inevitably have to master the language used by the nation's science progresses in the nation. Translations are also a major factor determining the progress of a nation and the majority of developed countries in the world is the State that the movement of translation in the country. And translation in history begins with the movement of translation into the language of Yunan, movement translations into Syriac, translation movement into Arabic in the khulafau arRashidun (Muawiyyah and Abbasyiyyah), move into a Latin translation, translation into the language movement modern Europe, modern translation movement into Arabic and other languages in the world of English as the language of the speakers was having to progress.
\end{abstract}

Keyword: at-Tarjamah, al-Lughah, al-Mutarjam minha, al-Mutarjam Ilaiha.

\footnotetext{
${ }^{1}$ Fakultas Ilmu Tarbiyah dan Keguruan, UIN Syarif Hidayatullah Jakarta
} 
علما له نظرياته، وبين "كاري Edmond Cary"

الترجمة جائت في العالم تلبية لحاجة الناس

للاتصال بين الشعوب المختلفة في العالم في الشتى

من بينها اللغة والثقافة واللون والجنس. ومن عادة الإنسان يحب حبا شديدا للتواصل والتعارف

وطلب العلوم من أخوته الذين عاشوا في نواحي ذلك العالم بمختلف شتى سابق. لذلك قام الإنسان بحركة الترجمة من لغة إلى لغة أخرى وعادة من اللغة المحتاجة معرفة ثقافتها وعلومها إلى اللغة نفسها. وفي هذه المقالة سيبحث تاريخ علم الترجمة ولكن قبل الوصول إليها يقدم الباحث البحوث عن معنى الترجمة، أنواع الترجمة، شروط المترجم، خطوات عملية الترجمة، الخلفية التاريخية، عوامل نشأة الترجمة، مراحل النمو والنشأة للترجمة، علم الترجمة: السلفي والقديم، علم الترجمة: ظهور نسق علمي، علم الترجمة: العربية، الغربية والإندونيسية والأخير يقدم الباحث الخلاصة من المقالة.

الترجمة ومعناها الترجة حقيقة هي عبارة ألمانية. ولقد

أطلق Harris سنة 1977 تسمية trantologie على علم الترجمة. وأتى فاسكيز (Vasquez) بمصطلح traductologie لكي تماثلها صرفيا وضم لاحقة لها: logie، لاكتسابها الجانب العلمي ولإبعادها عن معنى الفنية. وقد احتد الخلاف بين مدارس اللسانيات وعلى رأسها "فيدروف زنايدا، وفينأي، ودار بلناي" من وجهة اعتبارهم الترجمة
الذي يعبر الترجمة عملية أدبية فنية بالدرجة الأولى مقارنا بينها وبين المسرح مُ

والآخر قال أن الترجمة أصلها اللغوي من

اللغة العربية، ومعناها الأصلي أها بمعنى “،الشرح" باللغة الأخرى أونقل المعنى من اللغة إلى اللغة

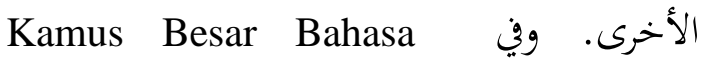
terjemahan salinan هن Indonesia suatu bahasa kepada bahasa lain. Menterjemahkan berarti menyalin atau memindahkan dari satu bahasa pada bahasa lain ووضحه والآخر قال أها نقل الكلام من لغة إلى أخرى والآخر أيضا قال سيراته وحياته . . وكما عبره الزرقاني الذي اقتطفه زكي أن معنى التزمة اللغوي أربعة: أ. توصيل الكلام إلى الآخر الذي كان ناقصا في استلام الكلام. وهذا التعريف يمكن في

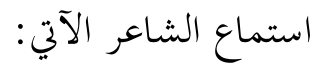

2سعيدة كحيل، نظريات الترجمة بحث في الماهية والممارسة، في أخي mohamedrabeea.com/books/book1_1150.pdf في يوم الخميس، 150 07 مارس 2013.ص. 1-2. ${ }^{3}$ M. Tata Taufik, Problematika Kebebasan Terjemah, dalam Jurnal Afaq Arabiyyah: Jurnal ebahasa araban dan Pendidikan Bahasa Arab, Jurusan Pendidikan Bahasa Arab, Fakultas Ilmu Tarbiyah dan Keguruan (FITK), uin Syarif Hidayatullah Jakarta, 2007, vol. 1, no. 2, Hal. 171.

${ }^{4}$ Toto Edidarmo, Distorsi Makna dalam Terjemah Kitab Riydhah al-Nasi Karya al-Ghazali, dalam Jurnal Afaq Arabiyyah: Jurnal Kebahasa araban dan Pendidikan Bahasa Arab, Jurusan Pendidikan Bahasa Arab, Fakultas Ilmu Tarbiyah dan Keguruan (FITK), uin Syarif Hidayatullah Jakarta, 2009, vol. 4, no. 2, Hal. 144..

${ }^{5}$ M. Zaka al Farisi, Pedoman Penerjemahan Arab Indonesia: Strategi, Mtode, Prosedru dan Teknik, Bandung: Remaja Rosdakarya, 2011, cet. ke.1, Hal. 22. 
إن الثمانين - وبلغتها - قد احوجت سمعي إلى ترجمان

"umur 80 dan aku sudah mencapainya telah membuat pendengaranku membutuhkan terjemah"

ب. شرح الكلام باللغة نفسها. مثلا قاموس المنجد في اللغة والأعلام، KBBI، وقد عرف ابن عباس بترجمان القرآن ومعناه مترجم أو شارح للقرآن.

ج. تفسير الكلام باللغة المختلفة مثلا تشرح اللغة العربية باللغة الإندونيسية وضددها. وفي هذا كان المترجم مفسرا للكلام. ومثال هذه الترجمة كتاب التفسير "المصباح" لقريش

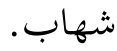
د. نقل الكلام من اللغة إلى الأخرى كنقل اللغة العربية إلى اللغة الإندونيسية وكما عبرها interlingual translation فئم Jacobson " وكان "penerjemahan antar bahasa" المترجم يعرف باسم "pengalih bahasa" في اللغة الإندونيسية.

ومن الكاملام السابق يعرف أن الترجمة حقيقة هي عملية النقل من الشيء إلى الآخر أو شرح الشيء بالشيء الآخر إما بنفسه أو بالآخر. وأما معنى الترجمة في الاصطلاح هو عملية تحويل الخطاب الذي في نص اللغة الأولى أو اللغة المصدرية (source language) بالمعادل في اللغة الثانية أو اللغة المهدوفة (target language). The New Oxford Dictionary of The power of translating تعبر English

${ }^{6}$ M. Tata Taufik, Problematika Kebebasan Terjemah, ...Hal. 171 words or text from one language in to 7 another ترجمة الكلمة أو النص من اللغة إلى الأخرى. وعبد الله وعبد العليم عبر أن الترجمة هي نقل الأفكار والأقوال من لغة إلى أخرى مع محافظة

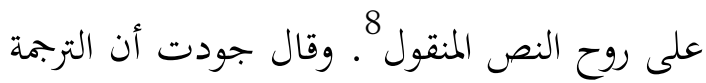
في فهمه هي محاولة نقل رسالة في اللغة المصدر إلى رسالة معادلة ها في في اللغة المنقول إليهاج وعرف الشباب أن الترجمة هي تأويل نص لغوي بكلام من غير لغته 10. والتعريف الآخر الترجمة هي إيصال فكرة أو إبلاغ أو قل هي التبليغ، او تحويل ذلك البلاغ إلى لغة أخرى، وإعطاؤها شكلا مكتوبا أو مسموعا، أو وضع صيغة مطابقة لصيغته في لغة الأصل، والترجمة الحقة هي التي

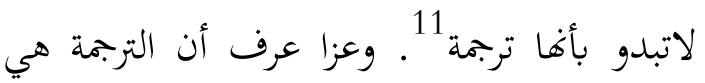
keterampilan (skillfull) menangkap pikiran yang diungkapkan dengan bahasa Arab atau bahasa lainnya kemudian menginformasikan pikiran itu kepada orang lain dengan bahasa indonesia atau 12 "sebaliknya secara lisan atau tulisan

${ }^{7}$ M. Tata Taufik, Problematika Kebebasan Terjemah, ...Hal. 171

أعبد العليم السيدمنسي و عبد الله عبد الرزاق إبراهيخ، الترجمة

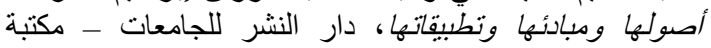

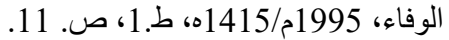
9ودوت حقمقي،، مقدمة في الترجمة (نمادج وتطبيقات من اللغة

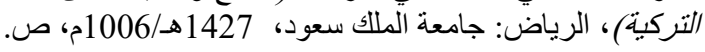

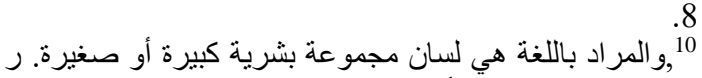

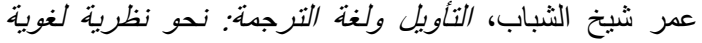

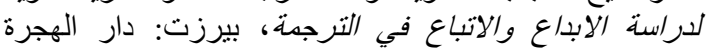

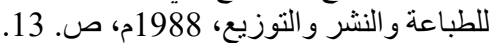
المحمد ديداوي، علم التنرجمة بين النظرية والتنطبيق، سوسة: دار المعارف للطباعة و النشر ، 1992، ص. ص. 15-16. ${ }^{12}$ Ahmad Izzan, Metodologi Pembelajaran Bahasa Arab, Bandung: Humaniora Mencerahkan Kehidupan, 2011, cet. ke 4., Hal. 182. 
ومن التعريفات السابقة تعرف أن في

الترجمة نقطتان أسايتان وهما النص والمعادل. والمراد

بالنص هو بمعناه الواسع ويمكن أن يكون أنه أنهات

حديث (wacana) ويككن أيضا أنه الوحدة

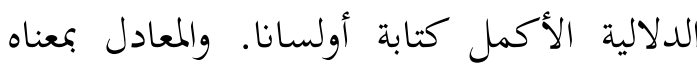

الواسع يعنى ليس فقط بديلا بين الكلمات

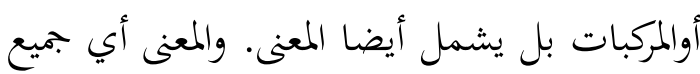

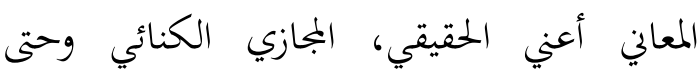

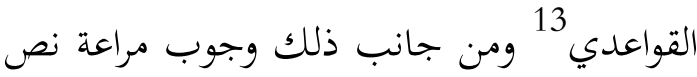

الترجمة من روححه الأصلي في اللغة المترجمة إليها.

والخلاصة من تاتا توفيق هي أن ترجمة حقيقة التهن

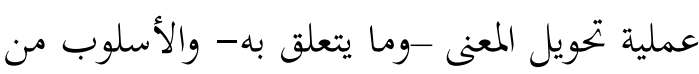
اللغة المصدرية إلى اللغة المهدوفة وحتى العامل العاطفي و السحري من النص موجوة في الترجمة14. والترجمة الجيدة هي الترجمة التي تستطيع التركي

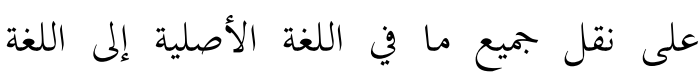

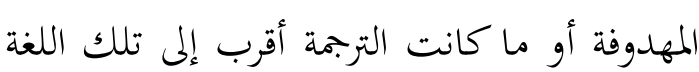

$$
\text { المهدوفة. }
$$

وتوتو قال أن في الترجمة أشياء تالية

1- عملية نقل المعنى من اللغة إلى الأخرى بالمراحل الخاصة ويخص الترجمة الصحيحة

$$
\text { والبديلة. }
$$

2- وهذه الصحيحة والمعادلة في الترجمة يجتاج

إلى استيعاب اللغنين أي المصدر والمهدوفة.

${ }^{13}$ M. Tata Taufik, Problematika Kebebasan Terjemah, ... Hal. 171

${ }^{14}$ M. Tata Taufik, Problematika Kebebasan Terjemah, ... Hal. 172.

${ }^{15}$ Toto Edidarmo, Distorsi Makna dalam Terjemah Kitab Riydhah al-Nasi Karya alGhazali, ... Hal. 145.
3- والمراد من الترجمة هو نقل المعنى البديل من

اللغة المصدر الم اللغة المهدوفة صحيحة

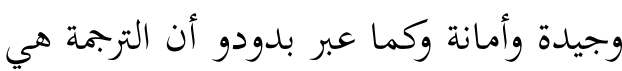

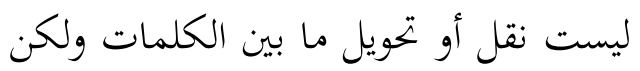
نقل الخطاب أو الفكرة أو الأمانة.

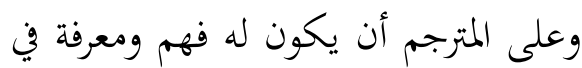

اللغتين وعليهم أن يتخلق بأخلاق كريمة مثل

الأمانة في نقل الفكرة أو الروح (value) الذي بلني كان في النصوص المترجم منها.

وحقيقة الترجمة عند زكي الفاريسي أهما

تحدف إلى تحصيل الترجمة التي تخضر المعنى الأقرب للمعنى في اللغة الأصلية/المصدرية. وطبقا لما عبرها reproducing in the أن التربمة هي Nida receptor language in the closet natural equivalent of the source language message, first in terms of meaning and secondly in terms of style استنساخ في اللغة المستقبلة في خزانة تعادل الطبيعية من اللغة المصدر رسالة، أولا من حيث المعنى وثانيا من حيث الأسلوب 16.

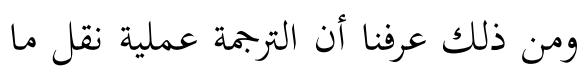

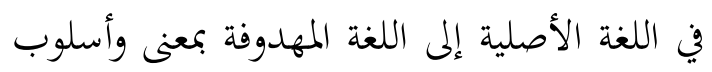

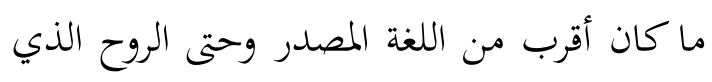

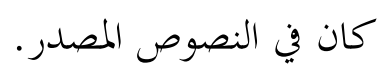

أنواع الترجمة وقال Jakobson كما اقتطفه الفاريسي قال أن التربمة تنقسم إلى ثلاثة وهي (1) الترجمة بين السميئوتيك (intersemiotic translation)

${ }^{16}$ M. Zaka al Farisi, Pedoman Penerjemahan Arab Indonesia:... Hal. 3. 
ويشمل الرمزين المختلفين مثلا ترجمة النوفيل إلى intra الفيلم: (2) الترجمة في اللغة الواحدة الترين مثلا من اللغة العربية إلى (lingual translation eka bahasa اللغة العربية كما كان في القاموس ومثاله قاموس "المنجد": (3) الترجمة بين اللغتين المختلفين (interlingual translation) الذي يشمل اللغتين المختلفين كما بين اللغة اللعربية والإندونيسية وبين اللغة الإنجليزية والعربية وغيرها 17. وقال الآخر أن أنواع الترجمة ثلاثة ألا وهي 18

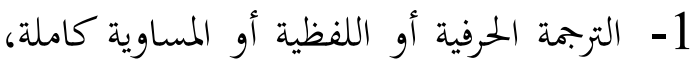

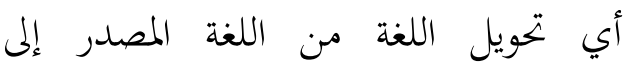

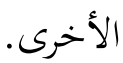

2- الترجمة المعنوية أو التفسيرية (restricted) الترجمة من اللغة إلى الأخرى ويهتم بالمعنى

$$
\text { والهدف من الترجمة. }
$$

3- الترجمة الحرية أو الديناميسية ( terjemah وهي (dinamis atau gaya bahasa bebas الترجمة التي توصل الأمانة في اللغة المصدر

$$
\text { بالعبارات اللازمة في اللغة المترجم إليها. }
$$

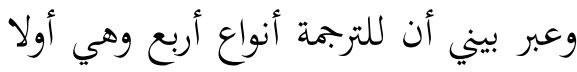

الترجمة كالصناعة (sains) وهي نطرة الترجمة التي تخصص فيما يتعلق باللغوية ولا غير. و وثانيا الترجمة والاستراتيجية (craft/kiat) وهي تنظر الترجمة كالاستراتيجية لمحاولة إدراك المقارن المناسب ويوفر العامل اللائق للغة المصدر أو الأصلي. وثالثا

${ }^{17}$ M. Zaka al Farisi, Pedoman Penerjemahan Arab Indonesia: ..., Hal. 2.

${ }^{18}$ Ahmad Izzan, Metodologi Pembelajaran Bahasa Arab, Bandung: Humaniora Mencerahkan Kehidupan, 2011, cet. ke 4., hal. $182-183$
الترجمة كالفن وهي تنظر إلى أن الترجمة ليس فقط

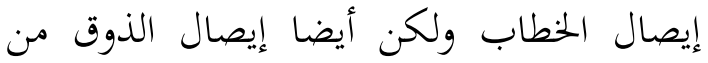
اللغة الأصلية وخاصة فيما يتعلق بالأدب والبحور البطال البعاب

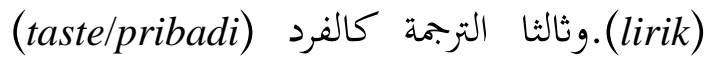
يعني أن الترجمة نتيجة حسب رغبة المترجم كالفرد ولا غير ومثاله في ترجمة كلمة however في اللغة الإنجليزية بamunlakan tetapi الإندونيسية حسب رغبة المترجم فيها 19

ومن الكلام السابق وضح لنا أن للترجمة

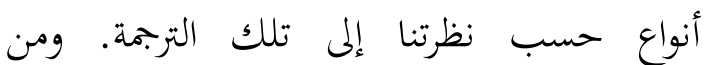
التقسيمات عرفنا أن من أنواع الترجمة من جانب التباع

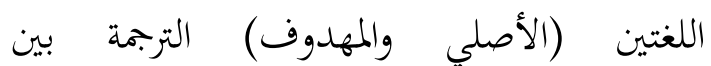
السميئوتيك والترجمة في اللغة الواحدة والترجمة بين اللغتين المختلفين. وأما من ناحية طريقة العبارة في اللغة المهدوفة تنقسم إلى الترجمة الحرفية أو اللفظية أو المساوية كاملة والترجمة المعنوية أو التفسيرية والترجمة الحرية أو الديناميسية. (restricted) شروط المتزجم وللترجمة عدة عوامل يجب أن تتوفر ومن بينها شروط واجب توفرها في المترجم وهي أ. إجادة اللغة التي ينقل منها وإليها. ب. إجادة القواعد اللغوية التي تحدد القنوات الفنية التي تنقل خلالها الأفكار الواردة في

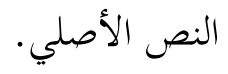

19 Benny Hoedoro Hoed, Penerjemahan dan Kebudayaan, Jakarta: Pustaka Jaya, 2006, cet. 1, Hal. 91-95

20 عبد العليم السيد منسي و عبد الله عبد الرزاق إير اهيم، الترجمة

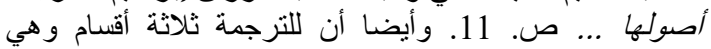

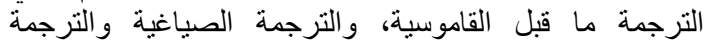
الفورية. و كتاب عمر شيخ الثباب، التأويل ولغة الترجمة: نحو

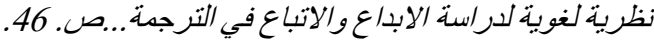


ج· إجادة خاصة لفروع العلوم المختلفة التي يقوم بالنقل منها وإليها، مع الإلمام بمصطلحاتا

$$
\text { والقدر الأعظم من مفرداها. }
$$

د. الأمانة في نقل الأفكار الواردة في النص الأصلي ونقلها بلغة واضحة وسلسلة

$$
\text { ومفهومة إلى اللغة المترجمة إليها. }
$$

هـ. محاولة بناء الفكرة في أسلوب مشابه إلى حد كبير للأسلوب الذي كتب فيه النص

$$
\text { الأصلي. }
$$

وهذه الشروط إشارة إلى أن نوعية الترجمة

تعتمد على نوعية المترجم وموقفه في عملية الترجمة بين اللغتين. ولأن الترجمة حقيقة أها فن وهو فن

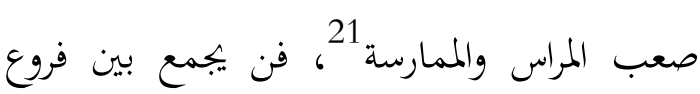
اللغة المنقول منها وإليها، ولذلك يجب على المترجم كما عبرها عبد العليم بالشروط التالية22: م قاعدة عريضة من مفردات اللغات التي يترجم سبم

$$
\text { منها وإليها. }
$$

O إلمام كامل بالمصطلحات والتعبيرات التي

$$
\text { تتميز كل لغة من اللغات. }
$$

م دراسة متعمقة للقواعد والنحو والبلاغة والبيان، بحيث يفهم المترجم المعنى في اللغة

الو الصعوبات في الترجمة هي (1) صعوبات في المفردات لأن المترجم ناقصا في استيلاء الكفردات اللغة المترجم من فئها أو إليها،

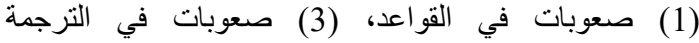
(transeliterasi)

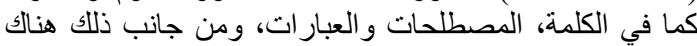
صعوبات أخرى أعني في غير اللغوية ألا وهي الصعوبات العبات

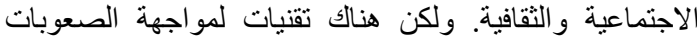
وهي (1) تويسع الترجمة بزيادة الكلمات النيات النافعة في اللغة

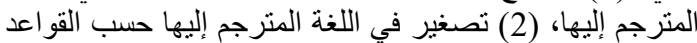
في اللغة المترجم إليها، و(3) تغيير التركيب حسب التئي التراكيب

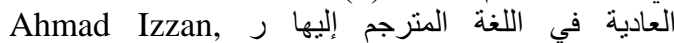
Metodologi Pembelajaran Bahasa Arab, ...., hal.

22 عبد العليم السيد منسي و عبد الله عبد الرزاق إبر اهيم، الترجمة

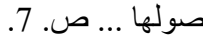

المترجم منها، ويعبر المترجم تعبيرات معادلة في اللغة المترجم إليها بالصيغ المعادلة. م خلفية علمية واسعة في العلوم التي يقوم بترجمة نصوصها مثل الأدب والتاريخ والطب والجغرافيا والكيمياء بحيث لا يخلتط معاني الألفاظ التي ترد في النص الذي يقوم بترجمته لأن كل العلوم مصطلحات خاصة والألفاظ المستخدمة فيها مختلفة. ومن الشروط الجديدة للترجمة كما عبرها عبد العليم على المترجم استيعاب العلوم التي يقوم بترجمة نصوصها مثل الأدب والتاريخ والطب والجغرافيا والكيمياء بحيث لا يختلط معاني الألفاظ التي ترد في النص الذي يقوم بترجمته لأن كل

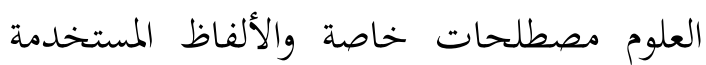
فيها مختلفة.

\section{خطوات عملية الترجمة}

إذا كان للترجمة معني، وأنواع وشروط المترجم فللترجمة مراحل او خطوات العملية وهي كما تلي 23: قراءة النص الأصلية أو المصدر 24

ورانسا ناظميان، الترجمة ومناهجها التطبيقية بين العربية

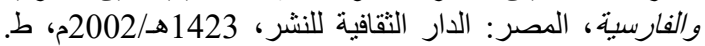

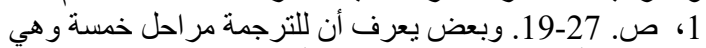

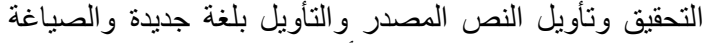

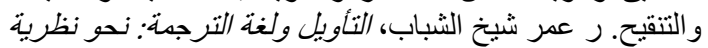

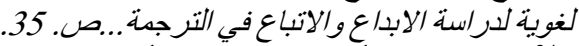

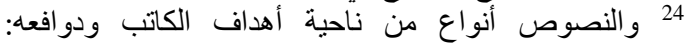

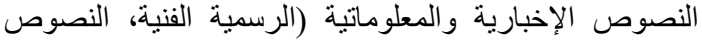

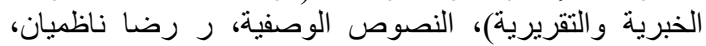

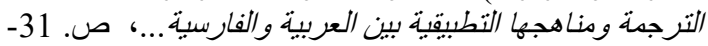

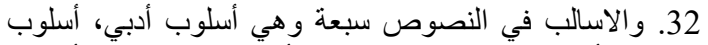

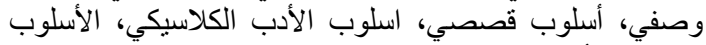
العلمي، الأسلوب الصحافي، والاسلوب، التوبل التجاري. ر ر Ahmad Izzan, Metodologi Pembelajaran Bahasa Arab, Bandung: Humaniora Mencerahkan Kehidupan, 2011, cet. ke 4., hal. 184-185. 
تحديد الكلمات الغريبة أو غير معروف وكسب معناها في القاموس 25

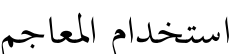

كتابة الترجمة في اللغة المهدوفة ومن الأحسن

$$
\text { باستخدام الحاسوب }
$$

إعادة النظر في النص المترجم وتقويمه

$$
\text { عملية تنقيح النص }
$$

وجب على المترجم عملية سابقة لتكون

الترجمة جيدة. ولمعرفة أن الترجمة جيدة ويجب علينا معرفة الشروط للترجمة الجيدة وهى وجوب تلبية المتطلبات الأساسية التالية 26 : - - تعكس المعنى بوضوح - - تنقل روح النص الأصلي وأسلوبه - - - تولد استجابة مشابهة في ذهن قارئها

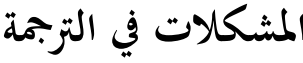

وفي الترجمة مشكلة لغوية وغير اللغوية.

ومن ناحية اللغة فللترجمة مشكلتان وهي المبنى والمعنى، ومن المبني هناك جانبان وهما قالب

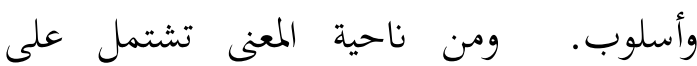

25 أشهر المعاجم العربية هي تنقسم إلى القسمين (1) القديمة:

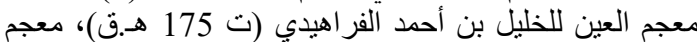

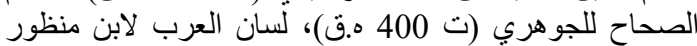

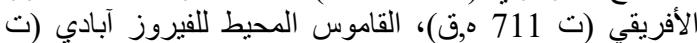

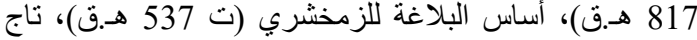

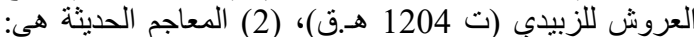

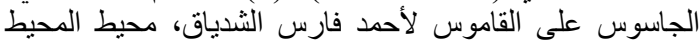

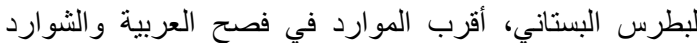

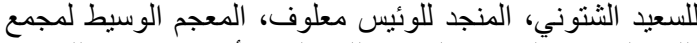

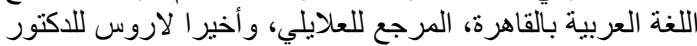

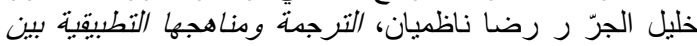
العربية والفارسية.... ص. ص. 10-15. 26جودت حقمقي، مقدمة في الترجمة ...، ص. 8.
المشكلات: تغيير المعنى، استخدام الاستعارة، المثل، درجة الاستخدام، والمعنى عرفا كما تلي 27:

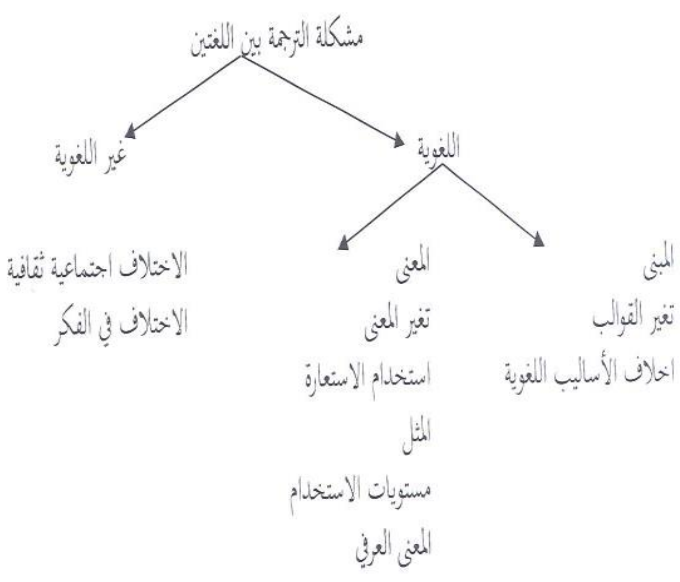

الحلفية التاريخية للتزجمة

كما عبرها التاريخ أن نجاح الدول

الإسلامية في بناء الحضارة مبتدأه هو عملية

الترجمة. والأعمال التي كتبها الفارسيون والمصريون

والهنديون وخاصة اليونانيون الذين يترجمون إلى رلى اللغة العربية. وكان عمود الحضارة الإسلامية لايمكن التفريق بالحضارة قبل الإسلام. وأنشطة الترجمة تدل على أن موقف الإسلام مفتوح إلى لـ

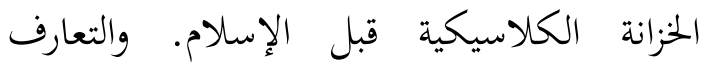
بالثقافات الكبيرة قبل الإسلام تزامن مع التوسع في الإمبراطورية الإسلامية إلى مناطق مختلفة خارج شبه الجزيرة العربية. وحث الإسلام لأمته على أن يتعلموا العلوم من من جاء ومن أين جاء العلم الذي دليله أنشطة الترجمة. وخلال القرنين تقريبا، من أول القرن السابع وحتى القرن الثامن تستمر

${ }^{27}$ Moh. Matsna HS, Kuliah Magister PBA, 27 Desember 2012. 
عملية الترجمة. وهذه ابتدأت في عهد المخليفة أبو

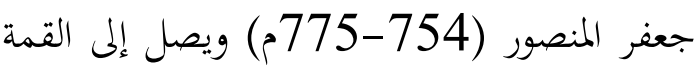
في عهد الخلفية المعصوم (813-833) وكانت المكتبة الكبيرة قد بناها الخليفة المأمون في بغداد. واسم بيت الحكمة صار اسما عظيما لمذه المكتبة. وعين الخليفة المأمون يوهانا بن ممسويه (ت. 857م) الذي كان كثرت ترجمته حول الطب الكلاسيكي رئيسا للمكتبة. وكان موافقة الخليفة تنشئ روح المسلمين العلمية في هذا العهد. وكانت المكتبة مركزا للترجمة والعلوم والمعرفة. والكتب مترجمة إلى اللغة العربية من اللغات المختلفة مثل لغة اليوناني، السورياني، الفارسي، العبراني، الهند، القبطي، النبطي، واللاتينية. وكان المترجمون الذين معظمهم نصارى الفيكي،

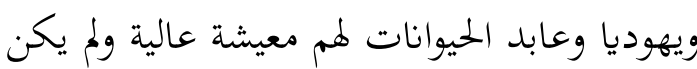
هذا في هذا الزمان.

والمترجم المشهور مثاله هو يهيى بن البتريق

(ت 815م) وهو قد ترجم الكتب الطيبية

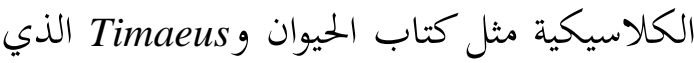

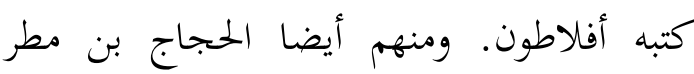
الذي كان عاش في عهد الخليفة المأمون وهو ترجم المجات الكتاب "Eulids" إلى اللغة العببية. ومنهم أيضا عبد المسيح بن نعيمة الحمسي (ت. 835م) وترجم كتاب "Sophistica" لأرسطو. والمترجم الآخر المنتج هو حنين بن إسحاق الأبدي، وهو النصراني النسطوري الني (810-873م). وحنين تجنيدهم من قبل يوحانا

${ }^{28}$ M. Zaka al Farisi, Pedoman Penerjemahan Arab Indonesia... Hal. 7.

${ }^{29}$ M. Zaka al Farisi, Pedoman Penerjemahan Arab Indonesia: ... Hal. 7.
بن مسكويه ومنه تعلم الطب وفي هذا الحين كان حنين متعدد اللغات وهو متقن في اللغات المختلفة الكثيرة. وله ترجمة كثيرة من أعمال اليونانيين والفارسيين، ومنها كتاب "politicus" و" لألفاطون والأخلاق والفيزياء لأرسطو. وتدفع الخليفة تربمته أعني حنين بالذهب الذي وزنه الكتب المترجمة وهذه شيع عظيم ولم يؤتيه أحد في هذا الزمان 30.

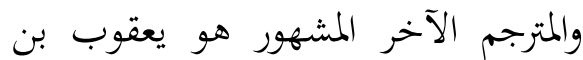

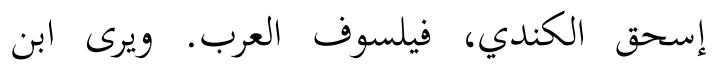
جلجل أنه ترجم من كتب الفلسفة الكثيرة. ومنهم أيضا ثاب بن قرة الحراني الصائبي، رئيس مدرسة حران، نبغ في علوم الطب والرياضيات والفلسفة

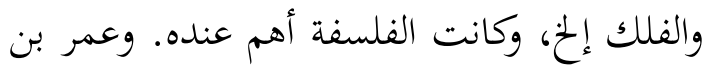
الفرخان الطبري وكان بريعا في علوم النجوم. والذين يأتي بعدهم إسحق بن حنين بن إسحق الذي كان أعرف بالعربية من أبيه، حبيش بن بن بن إسحن الحسن الأعسم، وهو طبيب، وقسطان بن لوقا البعلبكي، الطبيب الفيلسوف وأبو البشر بن وسطن

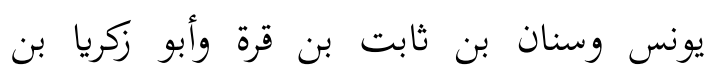
عدي، تلميذ الفارابي وعيسى بن إسحق بن زرعة وغيرهم 31

وكلهم مترجمون منتجون ولهم معيشة عجية وكبيرة وحياقم في مترف منعم لا كما كان المترجم في الدول غير المتقدم كما كان في إندونسيا الآن.

${ }^{30}$ M. Zaka al Farisi, Pedoman Penerjemahan Arab Indonesia: ....Hal. 8.

3حمد ديداوي، علم الترجمة بين النظرية والتطبيق، ...، ص. 
النمو والنشأة في الترجمة وتنقسم العهود إلى ستة عوامل نشأة التربمة

وطبعا لكل شيئ دوافع كعوامل نشئته

فللترجمة أيضا عوامل النشأة من بينها كما في دئ

عهودا وهي كما تلي 1-عهـ الترجمة إلى اللغة اليونانية:

أصبحت اللغة اليونانية واسعة ولغة الغة التهانية التالي:

1- عوامل اجتماعية: كان في ذلك القرن

التداول بين الفلاسفة والعلماء خارج نطاق أثينا

احتاجت الدولة إلى ترجمة الكتب والمعارف

في القرون الثلاثة قبل الميلاد. ومن آثارها في

لتنمية قدرة الدولة على استيلاء العالم.

مناطق شرق البحر الأبيض المتوسط ومصر مراكز

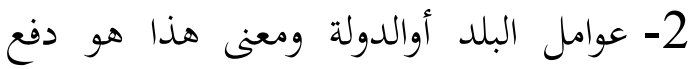

ثقافية في الإسكندرية وبعض المدن السورية.

الملك في الترجمة لأن الملوك كانوا يحبون العلوم

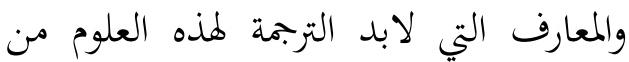

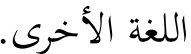

3- عوامل العلماء لحبهم على العلوم وتطورها.

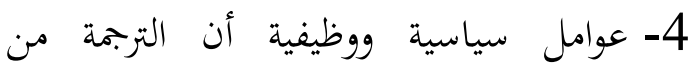

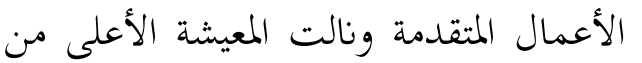

الكافية ولحياة مترفة منعمة.

وعبر شباك أن عامل أول للترجمة هو

الدين وحتى هذا العصر الحاضر. وبعده عامل

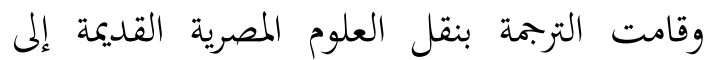
اللغة اليونانية ومن بينها ترجم "العهد القديم" باللغة اليوناية وأصل اللغة للكتاب هو اللغة

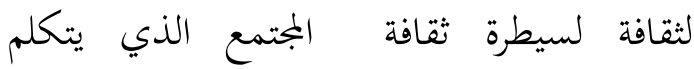

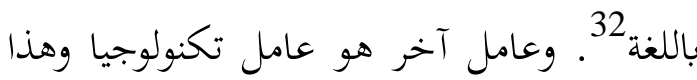

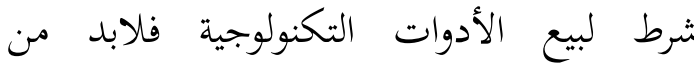
استخدام اللغة لدي الشعب المشتري للأدوات. كما كان في إندونيسيا عامل سيعمل في البلدان

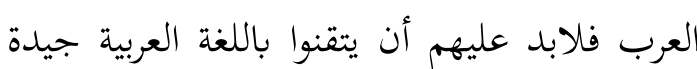

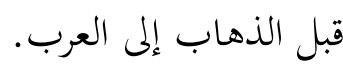

مراحل النمو والنشأة للتزبمة

وذكر الشباب في كتابه "التأويل ولغة

الترجمة" بابا اسمها عهود الترجمة التي تدل على لى لئل

32 مقابلة شخصية مع أحمد شباك السوداني، 07 مارس 2013.

333 شمر شيخ الثباب، التأويل ولغة الترجمة: نحو نظرية لغوية

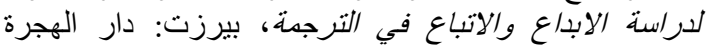
اللطباعة والنشر و التوزيع، 1988م، صاتلـ 62-68. 
اليونانية. وهذه الترجمات كنوز لاتقدر بثمن وفيما بعد (هذا التاريخ) ترجم إلى اللغة العربية.

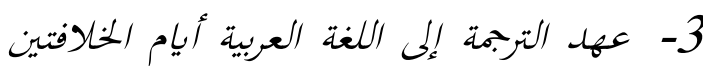

$$
\text { (الأموية والعباسية) }
$$

بلغ النشاط في الترجمة إلى اللغة العربية في عصر الخلافات أوجه في أواخر القرن الثاني للهجرة (القرن التاسع الميلادي وهذا يعنى ثمانية قرون بعد السرياني. وتحت رئاسة الخليفة العباسية، المأمون (813-833 ميلادي) الذي أقام مدرسة للترجمة. ورفعت المكانة العلمية للترجمة والمترجمين في ذلك العهد. وكانت الترجمة حقيقة ظهورها قد بدأت في عصر قبلها بدليل وجود كتاب الترجمة لكتاب "كليلة ودمنة" على يد ابن المقفع منذ القرن الأول للهجرة. ودليل مدى نشاط في الترجمة إلى اللغة العربية في أواخر القرن الثاني وأوائل القرن الثالث فإن المرء يجد ستمائة وتسعة وستين كتابا ومقالا نسبت ترجمتها إلى حنين بن اسحاق من اليونانية والسريانية إلى العربية. ولو أنه يرجح أن بعضها قد ترجم بعض الكتب وهو مشرف لهم، أو كان هو محسن ومصحح ومنقح ومرر للترجمات. وترجمت كتب لتب الفلسفة والعلوم وخاصة من اليونانية. بينما لم يشعر المسلمون بحاجة إلى كتاب الإنجيل والتوراة ولا المسرح اليوناني الذي يعتمد على تعدد الآلهة

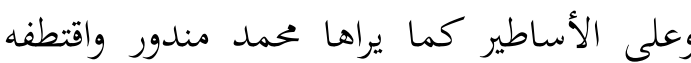
الشباب.

4- عهل الترجمة إلى اللغة اللاتينية احتك الأوروبيون بالعرب والمسلمين في الأندلس وجنوب إيطاليا وشواطئ شرقي البحر
الأبيض المتوسط، اهتمام بما وصلت إليه العلوم والفلسفة في أكناف الحضارة الإسلامية. وكان الرومان قد قاموا بترجمة العربيين أو غيرها من أصلتها ترجمة كتاب التوراة والإنجيل إلى اللاتينية على يد القديس جيروم (347-419 أو420). ونتائج هذه كانت كثيرة من الطلاب الغربيين ذاهبون إلى البلدان الإسلامية وخاصة إسبانيا -طالبا للمعرفة. وترجم الكتب العربية إلى لغتهم اللاتينية وحتى أمهات الكتب العلمية مثل كتاب "القانون في الطب" لابن سينا وأهم الأوروبيون بالحضارة الإسلامية وترجم الكتب من العلوم العربية من طب ورياضيات وعلم النجوم والأعشاب وغيرها من العلوم وكذلك الفلسفة العربية الإسلامية. ولكنهم فصلوا الجانب الديني والروحي للمسلمين عن ثقافتهم بدليل عدم ترجمتهم إلى القرآن الكريم. وساعدت هذه الحركة للترجمة من العربية إلى اللاتينية في القرن التاسع والعاشر والحادي عشر للميلاد الأوروبيين على إعادة اكتشاف الفلسفة والعلوم اليونانية القديمة من جهة والعلوم الإسلامية المزدهرة من ناحية

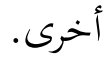
5- عهد الترجمة إلى اللغة الأوروبية الحلديثة بعد أن راجحت اللهجات المحلية المنحدرة من اللغتين اللاتينية والألمانية وغيرها، وأصبحت لغة مستقلة، ولاقت قبولا من مجتمعها. فاهتم الأوروبيون بالدراسات للآثار المكتوبة باللغة اللاتينية واليونانية (دراسات كلاسيكية). ووهذه الحركة تعرف باسم النقد الأدبي. وهي تمدف إلى الحصول على النصوص الصحيحة والمتعمدة 
للأعمال المتوفرة من التراث الكلاسيكي في مجالات العلوم والأدب ثم الكتاب المقدس. وبدأت الترجمات إلى اللغات الأوروبية

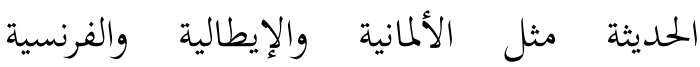
والإنكليزية منذ القرن الخامس عشر. ونتج عنه كثير من سلاسل الترجمات المعروفة على نطاق

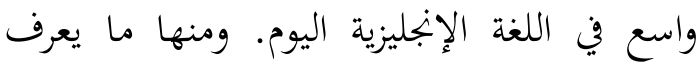
بكتاب مقدس وحتى أوسع ترجمات هذا الكتاب نفوذا في العالم الناطق بالإنكيزية حتى يومنا هذا.

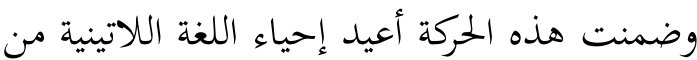
جديد، وترسخت لغة للعلم والعلماء في الجامعات الأوروبية. وحتى القرن الماضي بقيت اللغة اللاتينية كلغة علمية في بعض الجامعات الأوروبية. بينما ينحصر استعماها في بعض الطقوس الافتتاحية

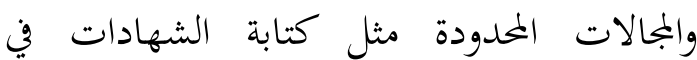

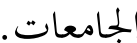

6- عهل الترجمة الحلديثة إلى اللغة العربية واللغات الأخرى في العالم من اللغة الإنجليزية كلغة الشعب المتقدم في العصر الحديث وأثناء حملة نابليون على مصر (1798-

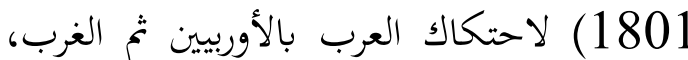
هذه الحالة لها أثثر كبير في الثقافة العربية وفي الحركة الفكرية والأدبية المعروفة بالنهضة العربية الحديثة. بدأت-عكس ما قبل__ترجمات من الغرب إلى العربية وكان دخول اللغات الفرنسية والإنكليزية وغيرهما إلى منطقة جبل لبنان عن طريق المدارس التبشيرية في النصف الثاني من القرن الماضي. الأمر

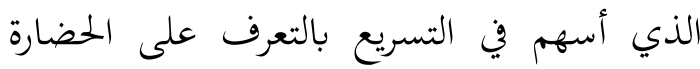
الغربية وبنشر أفكارها.
ولكن الترجمة إلى العربية في عصر الحديث

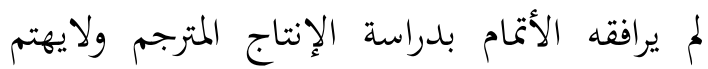
بظاهرة الترجمة ذاها. وأقسام الترجمة في الدول العربية أصبحت الغرض الأول منها تدريب وإنتاج المترجمين ترجمات جديدة إلا أن الكثير منها آتٍ

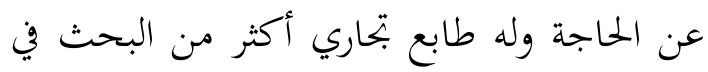
الترجمة أو زيادة معرفتنا عن هذه الظاهرة اللغوية عن طريق دراسة النصوص المتربمة وهو ما نسميه (لغة الترجمة). وهذا الإهمال في الترجة وعدم دراسة نظرية وافية لأسباب ثلاثة كما عبرها الشباب:

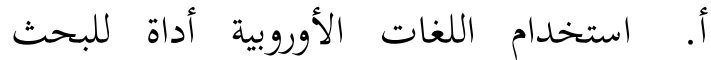
والتدريس في الجامعات العربية (ما عدا جامعة دمشف) وهذا يقلل الاحتياج إلى الترجمة.

ب. وجود مراكز جامعية في أوروبا تقوم بدراسة الترجمة من وإلى اللغة العربية، ففي بريطانيا وحدها هناك أربع عشرة رسالة جامعية أكثرها لنيل درجة الدكتورة في موضوعات تتعلق بالترجمة ونظرياتا ويدرس جميعها لهرها نصوصا تتعلق بالترجمة من اللغة العربية إلى

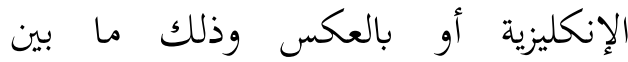
1950-1985م. وتزايد هذه الحالة بعد الإلحين افتتاح تدرس الماجستير في الترجمة في ثلاث جامعات بريطانية تركز على الترجمة من وإلى اللغة العربية من وإلى اللغة الإنكليزية.

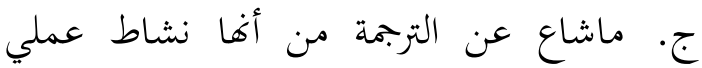
تجاري بحت، لكسب المال ليس غير، وهذا النشاط ليس له آية أبعاد علمية أو أهمية نظرية. 
هذه الحركة أي حركة الترجمة أيضا

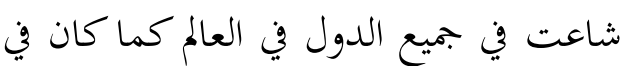

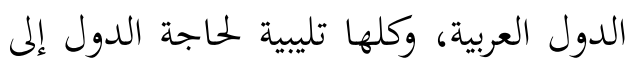
العلوم والمعارف في الشعوب المتكلمون باللغة الإنجليزية. ومن الأحسن معرفته أن كلا من عهود الترجمة يستخدم الترجمة التقليدية أي الي التحني

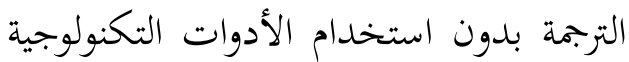
في إجراء الترجمة لا كما في عهد الترجمة الأخير أي الترجمة إلى اللغة العربية واللغات

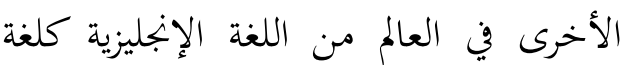
الشعب المتقدم في العصر الحديث. وأما في الإنيا العصر الحديث أي الترجمة إلى اللغة العببية واللغات الأخرى في العالم من اللغة الإنجليزية العدية كلغة الشعب المتقدم في العصر الحديث فكثير منها استخدام الأدوات التكنولوجية كمثل الترجمة بـوoogle ولكن استخدام هذا البرنامج لا يكفي في الحصول على الترجمة

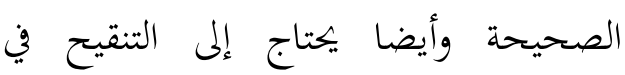
النواحي وخاصة في ناحية تراكيبية أو قواعدية.

\section{التزمة: السلفي والحديث/العصري}

للترجمة وظائف عظيمة في ترجمة العلوم والمعارف. وليس من المبالغة أن نذكر أن النهضة فرة النة في الدولة اليابانية كالدولة الصناعية المتقدمة دائما

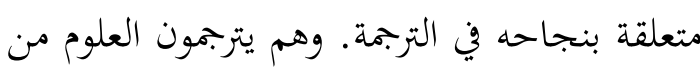

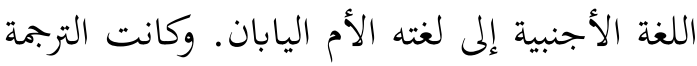

طريقة مثالية في نيل التقدم العظيم كما كان الآن 34.

وفي أول أمره كانت الترجمة فقط فنا

ولكن بعد القرن العشرين كانت الترجمة أيضا كانت الترة

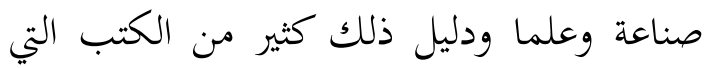
عبر بعبارة شديدة وهو علم الترجمة وليس فن الترجمة كما كان فيما قبل. وفي جامعة شريف هداية الله جاكرتا قسم اسمه قسم الترجمة في كلية الأدب والعلوم الإنسانية. والترجمة حقيقة هو حركة

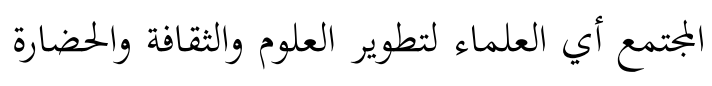

واتصف هذا العصر بضرورة الاتصال والارتباط والتعاون بين الدول في المجلات العلمية

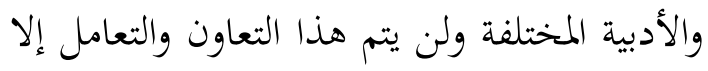
بالاستعانة بالترجمة التي تعتبر الركيزة الأساسية

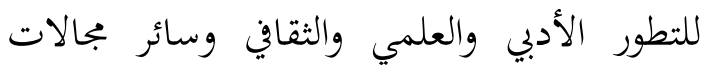

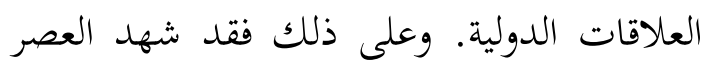
الحاضر تطورا ملحوظا لعملية الترجمة. ويظهر دوره جليا جدا في تنمية ثقافات قومية، وفي مسار تطور الثقافات العالمية والتبادل الثقافي الدولي فئل إن علماء الترجمة الذين يدرسون تاريخ

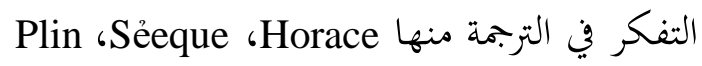
Le Jeune الأدب المتعلق بالترجمة في الغرب إلى أربع مراحل

\footnotetext{
${ }^{34}$ M. Zaka al Farisi, Pedoman Penerjemahan Arab Indonesia..., Hal. 6.

35 Muhbib, Kuliah sejarah-ilmu-ilmu kebahasaaraban, 2012.

وارضا ناظميان، الترجمة ومناهجها التطبيقية بين العربية والفارسي... ص. ص. 5. أمحمد أحمد طجو، مبادئ في علم الترجمة دانييل جيل، في www.reefnet.gov.sy/book
} 
1- - مرحلة التفكير التي تقوم على ممارسة الترجمة، والتي تبدأ من مبادئ شيشرون وهوراس

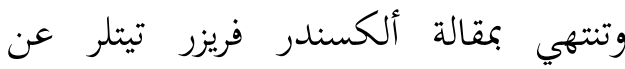

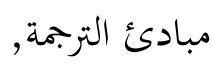
2- وتمتد المرحلة الثانية حتى نشر كتاب لاربو تحت حماية القديس جيروم (1946)، وتتميز بتوجهها التأويلي والنظري. 3- وتبدأ المرحلة الثالثة بالمطبوعات الأولى عن ولن الثطري

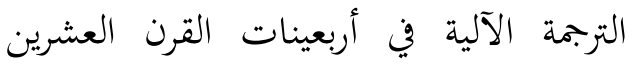
وبظهور اللسانيات البنيوية ونظرية التواصل. 4- بدأت في ستينات القرن العشرين وبعودة

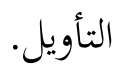

وهل الترجمة فن أو علم أو في اللغة

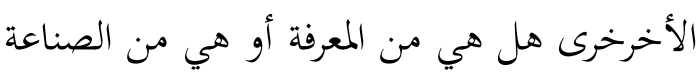

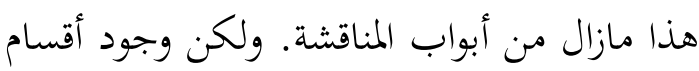

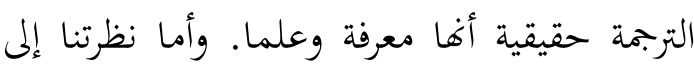

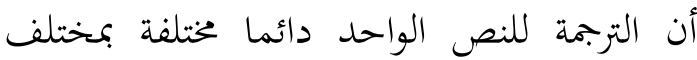

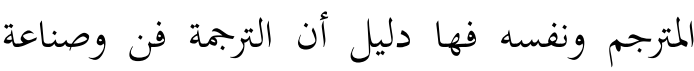

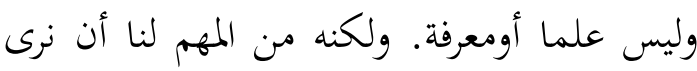

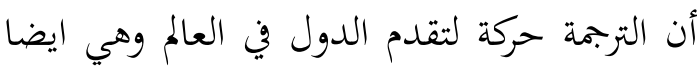
حرفة ذات معيشة عجيبة.

\section{التزبمة: ظهور نسق علمي}

لقد استمر دراسة علمية للترجمة، وجذب لقبي

عددا متزايدا من الجامعيين. وفي عام 1972م تم تحرير مقال مؤسس بقلم جيمس هولمز، تحت

sproject/adabajnabya/135/translate.pdf الخميس، 07 مارس 2013.ص. the عنوان "اسم دراسات الترجمة وطبيعتها" أو .name and nature of translation studies وهذا النص لم ينشر إلا في عام 1988م، يشير

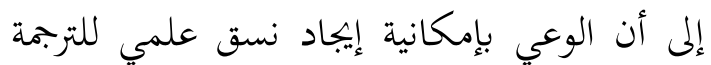

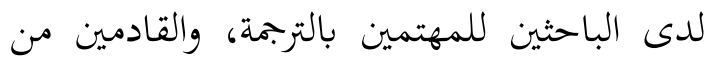
مجالات خختلفة مثل اللسانيات، وفقه اللغات، والدراسات الأدبية، ونظرية الإعلام، والمنطق والرياضيات. وييحث هولز في مناقشة مطولة في بداية المقال عن تسمية إنجليزية لهذا النسق العلمي الجديد. وكان هولز يجدد الترجمة وخاصة في لئي المصطلحات فيها علما تجريبيا وله هدفان وهو 38 أولا: وصف ظواهر الترجمية وثانيا: عرض نظريات

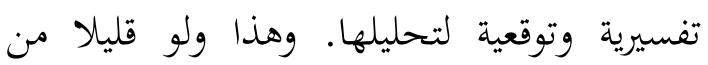
دلائل أن الترجمة في بعض وترفية لقحاء ألمفكرين هي من ولئ العلوم والمعرفة وليست صناعة أو فن كما يظنها ترجا

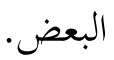

$$
\text { الترجمة في الغربية العربية والغربية والإندونيسية: العربة }
$$

وكان النصارى قد بنى الحضارة بترجمة الأعمال الربيين في القرن الخامس عشر الماسحي و الدول الأوروبية تؤجج renaissance ومعناه هو روح النهضة. وهذه النهضة لايتخلص عن وظيفة العلماء المسلمين الذين قد ولدوا الروح العلمي في

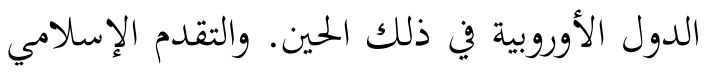

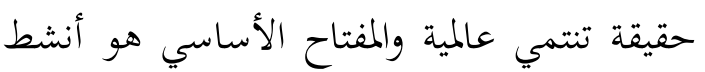
الترجمة 39 هذا من دلائل الترجمة في الدول الغربية

18-19 .20-19

39 M. Zaka al Farisi, Pedoman Penerjemahan Arab Indonesia ..., Hal. 8. 
لفهم العلوم التي كانت مكتوبة باللغة العربية كلغة الشعوب المتقدمة في ذلك العهد.

$$
\text { الترجمة في العربية }
$$

رغم الأهمية القصوى للترجمة إلا أها لا

تلقى في العصر الحاضر يومنا هذا نفس الاهتمام الذي لاقته في عصور النهضة الفكرية التي تميزيت بغزارة التعريب ووفرة الإنتاج الأدبي المترجم المنقول عن اللغات الأجنبية وبخاصة من اللغتين الإنجليزية والفرنسية. وقد يكون سبب ذلك هو (1) ابتحاه المفكرين إلى التأليف والابتكار ، (2) لقلة عدد

المتعمقين في اللغات المنقول منها وإليها، (3) لإحجام الكثيرين عن الإقدام على الترجمة، نظرا لانخفاض الأجر الذي يدفع للمترجم إذا ما قيس بأي عمل فكري أو يدوي آخر يمارسه الناس في الوقت الحاضر (4) للاتجاهات التعليمية الحديثة في الوطن العربي التي جعلت الترجمة فرعا عاديا من فروع اللغات التي تدرّس في مدارسها وكلياتا وجامعاما

فبرغم من أن اللغة العربية الجميلة تحتل

المرتبة السادسة من حيث عدد الناطقين بها وذلك بعد الصينية والإنجليزية والهندية والإسبانية والروسية، إلا أن الإحصاءات والدراسات تشير إلى تواضع حجم الترجمة في العالم العربي بالمقارنة

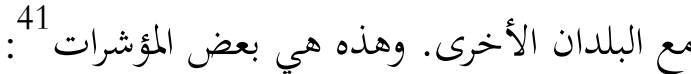

40 عبد العليم السيد منسي و عبد الله عبد الرزاق إبراهيم، الترجمة أصو لهاو ومبادئها وتطبيقاتها ...، ص. ص. 7.

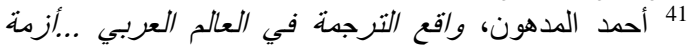
فاضحة ، الجمعية الدوليية للمثرجمين و اللغويين العرب ( World العربة (Association of Arab Translators \& Linguists http://www.wata.cc/forums/forumdisplay.php?60 -حركة_التزرجمة_في_الوطن_العربي، أخذ في يوم الخميس، 07
1- اليابان تترجم حوالي 30 مليون صفحة سنوياً. في حين أن ما يُترجم سنوياً في العالم العربي، هو حوالي خُمس ما يترجم في اليونان . والحصيلة الكلية لما ترجم إلى العربية منذ عصر المأمون [قتل عام813]] إلى العصر الحالي 10.000 كتاب؛ وهي تساوي ما تترجمه أسبانيا في سنة واحدة. وفي النصف الأول من ثمانينات القرن العشرين، كان متوسط الكتب المترجمة لكل مليون، على مدى خمس سنوات هو 4.4 كتاب (أقل من كتاب لكل مليون عربي في السنة) بينما في هنغاريا كان الرقم 519، وفي أسبانيا 920

2- إن عدد الكتب التي تُرجمت إلى العربية منذ ثلاثة عقود (1970-2000) وصل إلى 6881 كتابا، وهذا ما يعادل ما نقل إلى اللغة الليتوانية التي يبلغ عدد الناطقين بها قرابة أربعة ملايين إنسان فقط.

وإن تمام حسان مجدد النحو من مصر مترجما من اللغة الإنجليزية إلى اللغة العربية على الأقل خمس كتب بجانب كاتب لعشرة كتب ولايقل عن خمسين مقالات وبحوث علمية في المجلة والوطنية والدولية42. وهذه من الدليل الذي فيني يشرحنا أن حركة الترجمة في العربية الحديثة مازال بعيدا عن ما قامتها الدول المتقدمة في العالم.

$$
\text { الترجمة في الإندونيسية }
$$

وعلي سحبانا قد عبر أن الترجمة هو أنشطة استراتيجية، وهو اقترح على أن تكون

${ }^{42}$ Muhbib Abdul Wahab, Pemikiran Lingusitik Tammâm Hassân dalam Pembelajaran Bahasa Arab, Jakarta, UIN Jakarta Press, 2009. hal. 88. 
الترجمة سياسية وطنية. وكذلك قد عبر مولييونو (1995) عن أهمية الترجمة وهو عبر أن أنشطة الترجمة كانت أرخص ماليا وأكثر اقتصادية في الوقت بالنسبة للكلف والوقت لتعليم اللغات الأجنية (عربية، فرنسا، ألمانيا، يابان) علاوة على العلى العافية ذلك الهدف من التعليم في هذه اللغات الاستطاعة على فهم المقروء أو الترجمة للغة الإندونيسية الانسطة 43

هذا بالنسبة للغة الأجنبية كلغة العالم أو لغة التواصل بين اللغات للتواصل بين أفراد الإنسان المختلف في اللغة. وإن ما كان ينبغي هو درس اللغة أو تعلم اللغة بالطريقة القديمة وهي طريقة الترجمة. ومهما كانت هذه الطريقة ذات عيوب كما عبرها المثقف في علوم الطريقة ولكن لها مزايا كبيرة وهي اقتصادية وفعالة في تعليم اللغة العربية ولايمكن فصلنا في التدريس من هذه الطريقة القديمة والتقليدية-حسب أراء المفكر. وأما بالنسبة للغة العربية فترجمة هذه اللغة إلى الإندونيسية ذات أهمية ووظيفية كثيرة منها كما كان في اللغة العربية الأخرى كوسيلة اقتصادية لتعليم اللغة العربية. ومن جانبها كانت في الترجمة وظائف أخرى منها تعليم التعاليم الدينية والأخلاقية الإسلامسة وحضاراتا وثقافتها. ولأن معظم الإندونسين كانوا معتنقين بالإسلام ولغة الكتب الإسلامية مصادره الأساسية مكتوبة باللغة

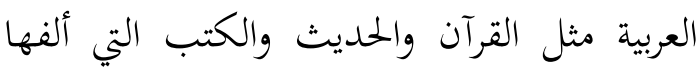
العلماء المسلمون بل كانت العبادات اليومية التي

43 M. Zaka al Farisi, Pedoman Penerjemahan Arab Indonesia... Hal. 9.
عملها المسلمون باللغة العربية فلا يصح العدول عنها. وحقيقة الترجمة في إندونيسيا هي حسب تلبية الحاجة الماسة من السوق أو المجتمع. ومثل هذا أن الكتب أو المقالة المترجمة من اللغة الأوروبية

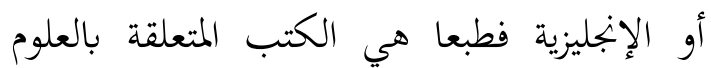

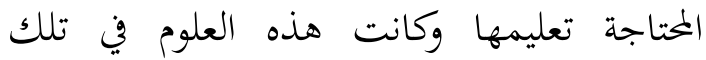
الكتب ونشأت في هذا الشعب. ومثال ذلك الكالك الكان كتب التكنولوجيا، طرقية التعليم، الإدارة، وغيرها من العلوم التي نشأت في الدولة التي يتكلم الشعب باللغة واحتاج الإندونيسيون إلى ترجمتها. وأما من اللغة العربية فكثير ما كان مترجما هو ما يتعلق بالعلوم الإسلامية والأخلاقية. ومثال ذلك هو ترجمة القرآن الكريم والحديث النبوي وكتب التفسير والكتب الأخرى مثل كتب الفقه وكتب التوحيد وكتب التاريخ وكتب النحو وكتب البلاغة وكتب المنطق وغيرها من الكتب التي وردت فيها العلوم التي دافع إعجاز القرآن الكريم والدعوة الإسلامية وجميعا مكتوب بالعبية. والترجمة في إندونيسيا حقيقية فقط فرديا وأهلية وحرفة وليست حكوميتا ولو كان هناك مترجم مقسم. وفي إندونيسيا كانت مهنة الترجمة متعلقة بالمهنة الأخرى وبعض المجتمع ينظر إلى أن إنان

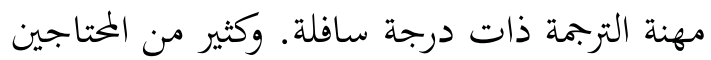
إلى الترجمة أكثر حبا لخيار المترجم غير المؤهل لأنه

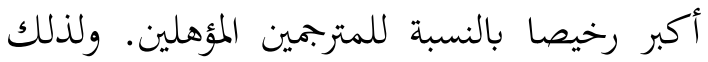
كانت الترجمة ذات جودة ناقصة عادة. ولتنمية درجة المهنة فلابد للمترجمين أن يعتمدوا على الى المعه أنفسهم وعليهم حس فخوري كالمترجم. وعليهم 
أن يكتبوا أسمهم في أول الكتاب المترجم وكذلك أيضا عليهم ذات مسؤولية في الترجمة لتكون

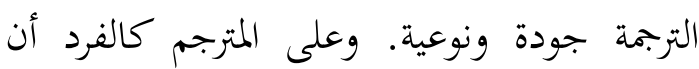

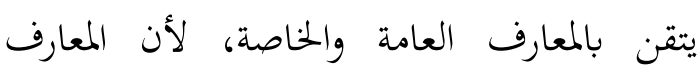
الخاصة تحتاج لترجمة العلوم الخاصة مثل القانون والتقنية والطب والضمان غيرها. ولكن المعارف

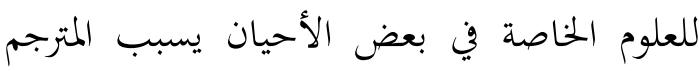
متهنئ للنص المترجم منها وحتى تكون نتيجة لهن التزجمة راسب أو غير جيد. ودرجة المترجم في لمتئ

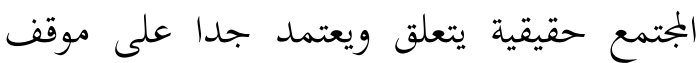
المترجمين أنفسهم حقبعية 44

\section{الخلاصة من المقالة}

ويستخلص الباحث في هذه المقالة أن المقلة

الترجمة حقيقة إنسانية لا يتجزأ عن الحاجة الإنسانية. لأن الإنسان مفطور باللغات المختلفة بين الشعوب والبلدان. وحقيقة الترجمة هي تلبية للحاجة إلى التعامل بين شعوب الدول المختلفة في اللغة. ولاسياما أن الإنسان مفطور بالحب للعلوم والتقدم العلمي وبينما كانت العلوم تطورت في

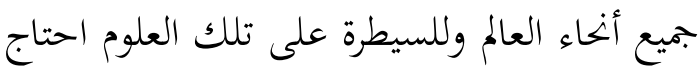
إلى اللغة المستخدمة في الشعب الذي تطور فيه

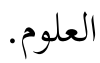

والترجمة أيضا باب من أبواب التقدم في

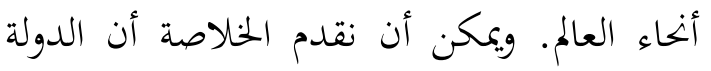
المثقدمة -على عادته- لا يمكن إلا بالعملية

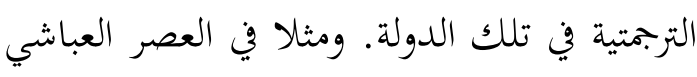
كانت التزجمة عامل مهم في تقدم هذه الدولة.
وكذلك اليابان يترجم حوالي 30 مليون صفحة

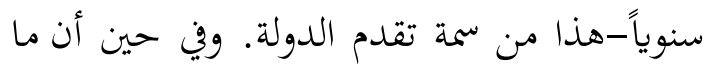

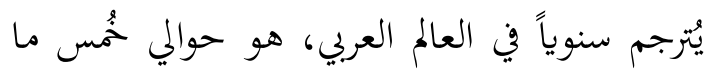

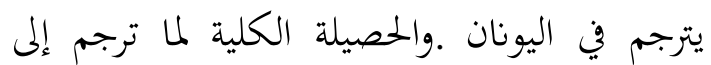

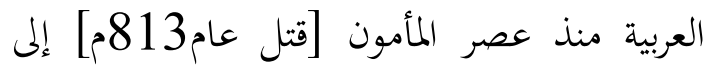
العصر الحالي 10.000 كتاب.

والترجمة أيضا حقيقة نقل المعنى وحتى

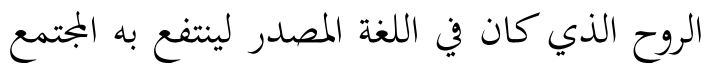
الناطق باللغة الأخرى. والترجمة الجيدة هي الترجمة التي تستطيع على حمل المعنى الذي كان في اللغة المترجم منها ووصفها باللغة المترجم إليها دقيقة. ولكن الحقيقة، ليست هناك ترجمة أحسن/معادل

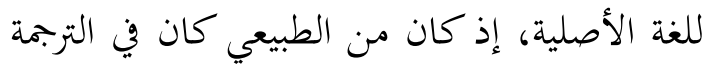

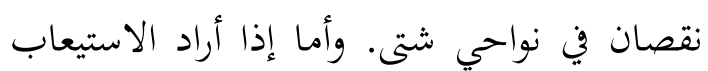

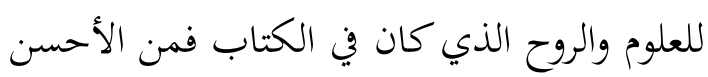

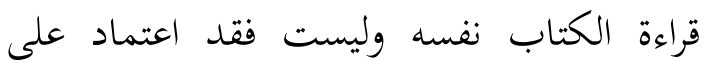

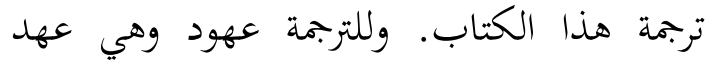
الترجمة إلى اللغة اليونانية، عهد الترجمة إلى اللغة السريانية، عهد الترجمة إلى اللغة العربية أيام

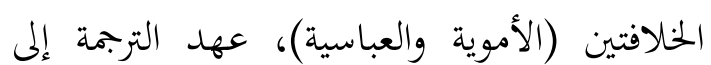
اللغة اللاتينية، عهد الترجمة إلى اللغة الأوروبية الحديثة، وعهد الترجمة الحديثة إلى اللغة العربية واللغات الأخرى في العالم من اللغة الإنجليزية كلغة

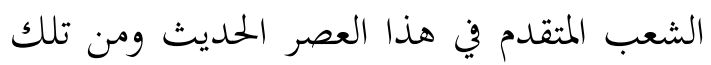
اللغة أيضا لغة إندونيسية. والله أعلم.

\footnotetext{
44 Benny Hoedoro Hoed, Penerjemahan dan Kebudayaan ..., Hal. 130.
} 


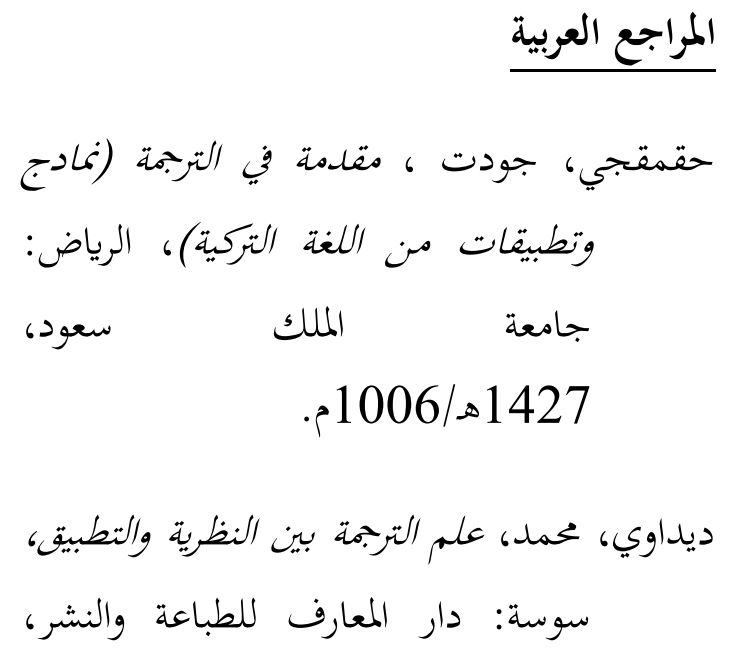

.1992

السيد منسي، عبد العليم وعبد الله عبد الرزاق إبراهيم، الترجمة أصولها ومبادئها

وتطبيقاتا، دار النشر للجامعات

مكتبة الوفاء، 1995 1415هـ، .1.b

الشباب، عمر شيخ، التأويل ولغة الترجمة: نحو

نظرية لغوية للدراسة الابلاع والاتباع في

الترجمة، بيرزت: دار الهجرة للطباعة

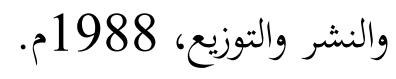

طجو، محمد أحمد، مبادئ في علم الترجمة دانييل

جيل، في www.reefnet.gov.sy/book sproject/adabajnabya/135/translat e.pdf أخذ في يوم الخميس، 07 مارس

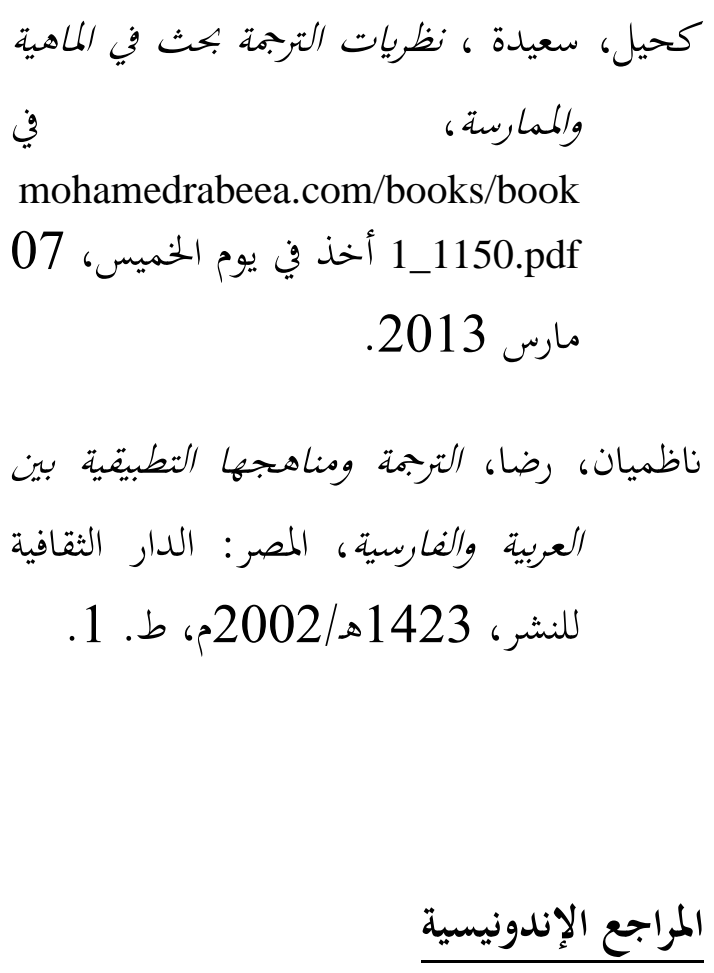

Abdul Wahab, Muhbib, Pemikiran Lingusitik Tammâm $\underline{\text { Hassân }}$ dalam Pembelajaran Bahasa Arab, Jakarta, UIN Jakarta Press, 2009.

al Farisi, M. Zaka, Pedoman Penerjemahan Arab Indonesia: Strategi, Mtode, Prosedru dan Teknik, Bandung: Remaja

Rosdakarya, 2011, cet. ke.1.

Edidarmo, Toto, Distorsi Makna dalam Terjemah Kitab Riydhah al-Nasi Karya al-Ghazali, dalam Jurnal Afaq Arabiyyah: Jurnal Kebahasa araban dan Pendidikan Bahasa Arab, Jurusan Pendidikan Bahasa Arab, Fakultas Ilmu Tarbiyah dan Keguruan (FITK), uin Syarif Hidayatullah Jakarta, 2009, vol. 4, no. 2 .

Hoed, Benny Hoedoro, Penerjemahan dan Kebudayaan, Jakarta: Pustaka Jaya, 2006, cet. 1.

Izzan, Ahmad, Metodologi Pembelajaran Bahasa Arab, 
Bandung: Humaniora

Mencerahkan Kehidupan, 2011, cet. ke 4.,

Taufik, M. Tata, Problematika Kebebasan Terjemah, dalam Jurnal Afaq Arabiyyah: Jurnal ebahasa araban dan Pendidikan Bahasa Arab, Jurusan Pendidikan Bahasa Arab, Fakultas Ilmu Tarbiyah dan Keguruan (FITK), uin Syarif Hidayatullah Jakarta, 2007, vol. 1, no. 2. 